1912 $\begin{array}{r}\text { Media Ilmiah Teknik Lingkungan } \\ \text { Volume 3, Nomor 1, Februari 2018 } \\ \text { Artikel Hasil Penelitian, Hal. 30-36 }\end{array}$

\title{
Tanggapan Masyarakat Terhadap Rencana Pengembangan Kawasan Waterfront City Di Sungai Arut Pangkalan Bun
}

\author{
Trissiyana \\ Program Studi Teknik Sipil Fakultas Teknik Universitas Antakusuma Pangkalan Bun
}

\begin{abstract}
ABSTRAK. Sungai Arut merupakan anak Sungai Lamandau, sungai ini memiliki panjang kurang lebih $250 \mathrm{Km}$, dengan kedalaman rata-rata 4 - 6 meter dan lebar rata-rata 36-100 meter. Panjang Sungai Arut yang dapat digunakan untuk alur pelayaran sepanjang $190 \mathrm{Km}$. Adapun tujuan dari penelitian ini adalah untuk mengetahui tingkat tanggapan masyarakat pinggiran Sungai Arut mengenai rencana pengembangan Waterfront City pada pinggiran Sungai Arut Pangkalan Bun. Metode yang digunakan untuk acuan dalam analisis data pada penelitian ini memakai Metode Statistik Deskriptif, Metode statistic Nilai Rata-rata (Mean) dan Metode statistic, Nilai Presentase dengan menggunakan bantuan program SPSS versi 22. Berdasarkan hasil penelitian dapat disimpulkan bahwa faktor pengembangan kawasan dengan mean 3,82 menjadi faktor dengan nilai mean tertinggi yang mempengaruhi tingkat tanggapan masyarakat pinggiran Sungai Arut terhadap rencana pengembangan Waterfront City di sungai Arut Pangkalan Bun.
\end{abstract}

Kata kunci: sungai arut, tingkat tanggapan, waterfront city, metode statistik, faktor pengembangan kawasan

\section{PENDAHULUAN}

Indonesia merupakan negara kepulauan yang terdiri dari 17.503 pulau termasuk di dalamnya pulau besar dan kecil. Indonesia sering di sebut juga sebagai negara maritim. Hal ini dikarenakan tiga perempat wilayah Indonesia terdiri dari laut atau sekitar 5,9 juta km. Pembangunan Nasional Bangsa Indonesia merupakan kegiatan pembangunan yang di laksanakan secara bertahap dan berkelanjutan, dimana pada setiap tahapnya diharapkan dapat memberikan hasil pembangunan yang terus meningkat serta dapat dirasakan manfaatnya secara merata oleh seluruh rakyat. Pangkalan Bun adalah Ibukota Kabupaten Kotawaringin Barat di Kalimantan Tengah. Luas wilayah Kabupaten Kotawaringin Barat tercatat 10.759 km. Di Kabupaten Kotawaringin Barat terdapat tiga sungai besar yakni Sungai Arut,
Sungai Lamandau, Sungai Kumai, dan puluhan anak sungai.

Sungai Arut merupakan Anak Sungai Lamandau, sungai ini memiliki panjang kurang lebih $250 \mathrm{~km}$, dengan kedalaman ratarata 4- 6 meter dan lebar rata-rata 36-100 meter. Panjang Sungai Arut yang dapat digunakan untuk alur pelayaran sepanjang 190 km. Kawasan di sekitar DAS Arut mudah tergenang, berawa-rawa, dan merupakan daerah endapan serta bersifat organik dan asam.

Sebagai sungai yang digunakan masyarakat untuk melakukan berbagai macam kegiatan, terdapat beberapa permasalahan pada Sungai Arut, terutama pada penataan daerah pinggiran sungai, sampah yang menumpuk di bawah perumahan masyarakat, tata letak toilet atau sering di sebut jamban yang tidak teratur, akses jalan yang berbahan 
kayu bulin dan sempit sehingga tidak dapat di lalui transportasi jenis roda empat yang membuat masyarakat sulit untuk berinteraksi dan bersosialisasi.

Dengan beberapa permasalahan diatas pemerintah Kabupaten Kotawaringin Barat merencanakan untuk membangun Waterfront City dibantaran pinggiran Sungai Arut dengan tujuan memperbaiki penataan pada pinggiran Sungai Arut terutama akses jalan sehingga dapat dilalui transportasi jenis roda empat. Melihat dari permasalahan yang ada diperlukan adanya penelitian tentang tanggapan masyarakat pinggiran Sungai Arut mengenai rencana pengembangan Waterfront City pada pinggiran Sungai Arut Pangkalan Bun. Di harapkan penelitian dapat di gunakan pemerintah sebagai acuan dan mengetahui bagaimana tanggapan masyarakat pinggiran Sungai Arut tentang Pembangunan Waterfront City.

Secara umum Waterfront adalah konsep pengembangan daerah tepian air baik itu tepi pantai, sungai ataupun danau. Waterfront juga dapat diartikan suatu proses dari hasil pembangunan yang memiliki kontak visual dan fisik dengan air dan bagian dari upaya pengembangan wilayah perkotaan yang secara fisik alamnya berada dekat dengan air dimana bentuk pengembangan pembangunan kota yang berorientasi ke arah perairan.

\section{METODE PENELITIAN}

Jenis penelitian ini merupakan jenis penelitian deskriptif statistik, karena dalam penelitian ini mendeskripsikan keadaan yang terjadi pada saat sekarang secara sistematis dan faktual dengan tujuan untuk memaparkan serta penyelesaian dari masalah yang diteliti. Menurut Nawawi (1991) metode deskriptif adalah prosedur pemecahan masalah yang diselidiki dengan menggambarkan / melukiskan keadaan / subyek / obyek penelitian (seseorang, lembaga, masyarakat dan lain-lain) pada saat sekarang berdasarkan fakta-fakta yang tampak sebagaimana adanya.

Alur dalam penelitian ini dimulai dengan melakukan studi pendahuluan yang meliputi : Pengenalan daerah studi, tinjauan pustaka, identifikasi data yang akan di gunakan untuk penelitian. Dari studi pendahuluan yang dilakukan, dilanjutkan identifikasi masalah sehingga dapat disusun latar belakang masalah dan rumusan masaslah serta penetapan tujuan penelitian ini.

Selanjutnya dilakukan pengumpulan data baik data primer maupun dari data sekunder. Data primer dalam penelitian ini diperoleh melalui kuisioner atau wawancara kepada masyarakat pinggiran Sungai Arut Pangkalan Bun. Sedangkan data sekunder dalam penelitian ini diperoleh dari data perencanaan Waterfront City.

\section{HASIL DAN PEMBAHASAN}

Untuk mengukur pengaruh masingmasing variabel dalam penelitian ini di gunakan skala $1-4$ dengan kriteria tertentu.Berikut tabel kriteria pengukuran variabel pada penelitian ini.

Tabel 1 Kriteria Pengukuran Variabel

\begin{tabular}{cccc}
\hline \multicolumn{2}{c}{ Skor jawaban } & \multicolumn{2}{c}{ Kriteria } \\
\hline Skala & Keterangan & Mean & Keterangan \\
\hline \multirow{2}{*}{1} & Sangat tidak & $1,00-1,50$ & $\begin{array}{c}\text { Sangat } \\
\text { Rendah }\end{array}$ \\
& Setuju & & Rendah \\
2 & Tidak & $1,51-2,50$ & Retuju \\
3 & Setuju & $2,51-3,50$ & Tinggi \\
4 & Sangat & $3,51-4,00$ & Sangat \\
& Setuju & & Tinggi \\
\hline
\end{tabular}

Deskripsi kriteria dan urutan masingmasing variabel secara ringkas ditampilkan dalam tabel berikut ini: 
Tabel 2 Kriteria Skor dan Urutan Variabel Penelitian

\begin{tabular}{|c|c|c|c|c|}
\hline & Faktor & Mean & Kriteria & Urutan \\
\hline & $\begin{array}{l}\text { tor-Faktor yang mempengaruhi Masyarakat } \\
\text { htruksi Pembangunan Waterfront City }\end{array}$ & & & \\
\hline $\mathbf{A}$ & Faktor Penataan Kawasan Lingkungan & 3,28 & Tinggi & $\mathbf{V}$ \\
\hline 1 & Pelabuhan getek di pusatkan satu wadah & 3,10 & Tinggi & 4 \\
\hline 2 & Pembaharuan jembatan & 3,76 & Sangat Tinggi & 1 \\
\hline 3 & Keramba/Tambak ikan tidak ada lagi & 3,14 & Tinggi & 2 \\
\hline 4 & Jamban di ganti dengan toilet umum & 3,12 & Tinggi & 3 \\
\hline $\mathbf{B}$ & Faktor Sosialisasi Masyarakat & 3,59 & Sangat Tinggi & III \\
\hline 1 & Tidak merasa nyaman & 3,14 & Tinggi & 4 \\
\hline 2 & Dibangun jalan dengan kontruksi Pile slab & 3,72 & Sangat Tinggi & 3 \\
\hline 3 & Kontruksi dibangun sepanjang Sungai Arut & 3,76 & Sangat Tinggi & 1 \\
\hline 4 & Sikap dan presepsi terhadap proyek & 3,74 & Sangat Tinggi & 2 \\
\hline $\mathbf{C}$ & Faktor Pelaksanaan Pembangunan & 3,40 & Tinggi & IV \\
\hline 1 & Alur transportasi terganggu & 3,38 & Tinggi & 2 \\
\hline 2 & Alat kontruksi membuat kebisingan & 3,42 & Tinggi & 1 \\
\hline $\mathbf{D}$ & Faktor Pengembangan Kawasan & 3,82 & Sangat Tinggi & I \\
\hline 1 & Roda empat dapat beroprasi & 3,82 & Sangat Tinggi & 1 \\
\hline 2 & Menjadi daya tarik wisata & 3,82 & Sangat Tinggi & 1 \\
\hline 3 & Banyak peluang usaha & 3,82 & Sangat Tinggi & 1 \\
\hline $\mathbf{E}$ & Faktor operasional dan pemeliharaan & 3,63 & Sangat Tinggi & II \\
\hline 1 & Menjaga dan melestarikan & 3,70 & Sangat Tinggi & 1 \\
\hline 2 & Tidak mencemari air sungai & 3,50 & Tinggi & 2 \\
\hline 3 & Pemeliharaan rutin & 3,70 & Sangat Tinggi & 1 \\
\hline
\end{tabular}

Sumber data : Data primer yang diolah , 2018

Tabel 3. Rangking Faktor-Faktor Yang Mempengaruhi Tanggapan Masyarakat Terhadap Rencana Pengembangan Kawasan Waterfront City Di Sungai Arut Pangkalan Bun

\begin{tabular}{clc}
\hline Urutan & $\begin{array}{l}\text { Rangking Faktor-Faktor Yang Mempengaruhi Tanggapan Masyarakat } \\
\text { Terhadap Rencana Pengembangan kawasan Waterfront City di Sungai } \\
\text { Arut Pangkalan Bun }\end{array}$ & Mean \\
\hline 1 & Faktor Pengembangan Kawasan & 3,82 \\
2 & Faktor Operasional dan Pemeliharaan & 3,63 \\
3 & Faktor Sosialisasi Masyarakat & 3,59 \\
4 & Faktor Pelaksanaan Pembangunan & 3,40 \\
5 & Faktor Penataan Kawasan Lingkungan & 3,28 \\
\hline
\end{tabular}




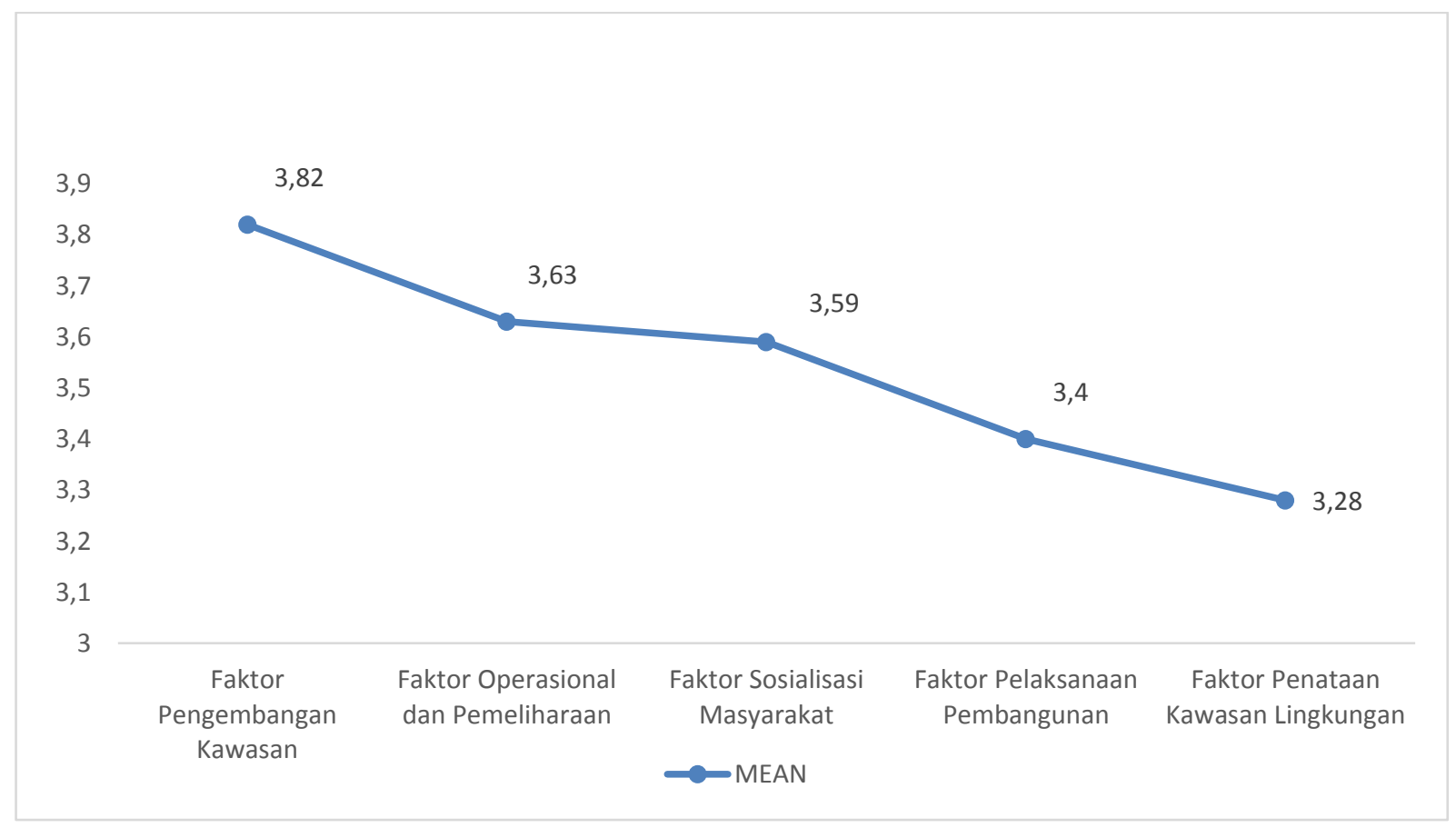

Gambar 1 Grafik Urutan Rangking Faktor-Faktor Yang Mempengaruhi Tanggapan Masyarakat Terhadap Rencana Pengembangan kawasan Waterfront City di Sungai Arut PangkalanBun

Dari hasil Tabel 3 dan Grafik 1 di ketahui bahwa faktor Pengembangan kawasan merupakan faktor yang sangat mempengaruhi tanggapan masyarakat terhadap rencana pengembangan Kawasan Waterfront City di Sungai Arut Pangkalan Bun, dengan ini dapat terlihat bahwa masyarakat bantaran Sungai Arut ingin kawasan mereka dapat berkembang menjadi kawasan yang lebih modern, dengan begitu kawasan tersebut dapat menjadi daya tarik wisata.

Dari Tabel 3 Rangking Faktor-faktor yang mempengaruhi tanggapan masyarakat terhadap rencana pengembangan Kawasan Waterfront City di Sungai Arut Pangkalan Bun, Dapat dijelaskan Sebagai Berikut :

1. Faktor Pengembangan Kawasan

Faktor pengembangan kawasan dengan nilai mean 3,82 (Kriteria Sangat Tinggi), merupakan faktor yang sangat mempengaruhi tanggapan masyarakat terhadap rencana pengembangan Kawasan Waterfront City di Sungai Arut Pangkalan Bun, pada Faktor pengembangan kawasan terdapat 3 faktor didalamnya yaitu roda empat dapat beroprasi, menjadi daya tarik wisata, dan banyak peluang usaha, ke-3 faktor tersebut memiliki nilai mean yang sama 3,82 (Kriteria Sangat Tinggi) yang berarti semua pertanyaan pada faktor pengembangan kawasan sangat mempengaruhi tanggapan masyarakat terhadap rencana pengembangan Kawasan Waterfront City di Sungai Arut Pangkalan Bun. Berdasarkan hasil wawancara langsung kepada masyarakat bantaran Sungai Arut, ada beberapa masukan dari masyarakat yaitu masalah pelabuhan getek yang akan dijadikan beberapa titik atau di pusatkan satu wadah, menurut bebrapa warga hal ini memang membuat Sungai Arut lebih tertata dan nyaman di pandang, namun akan merugikan bebrapa warga yang bertempat tinggal jauh dari pelabuhan getek yang akan menempuh jarak yang 
cukup jauh dan memakan waktu untuk menuju pelabuhan getek tersebut.

2. Faktor Operasional dan Pemeliharaan Faktor operasional dan pemeliharaan memiliki nilai mean 3,63 (Kriteria Sangat Tinggi), terdapat 3 faktor di dalamnya yaitu menjaga dan melestarikan, tidak mencemari air sungai, pemeliharaan rutin, yang merupakan faktor mempengaruhi tanggapan masyarakat terhadap rencana pengembangan Kawasan Waterfront City di Sungai Arut Pangkalan Bun, dan ada 2 faktor yang memiliki nilai mean yang sama dan tinggi 3,70 (Kriteria Sangat Tinggi) yaitu faktor menjaga dan melestarikan dan pemeliharaan rutin, yang berarti kedua faktor tersebut sangat mempengaruhi tanggapan masyarakat terhadap rencana pengembangan Kawasan Waterfront City di Sungai Arut Pangkalan Bun.

\section{Faktor Sosialisasi Masyarakat}

Faktor sosialisasi masyarakat dengan nilai mean 3,59 (Kriteria Sangat tinggi),terdapat 4 faktor di dalamnya yaitu tidak merasa nyaman, dibangun jalan dengan kontruksi pile slab, kontruksi dibangun sepanjang sungai arut, serta sikap dan presepsi terhadap proyek. Faktor yang memperngaruhi tanggapan masyarakat terhadap rencana pengembangan Kawasan Waterfront City di Sungai Arut Pangkalan Bun, dan faktor sosialisasi masyarakat urutan 1 yang mempengaruhi responsi masyarakat dalam menanggapi pra kontruksi pembangunan Waterfront City dibantaran Sungai Arut Pangkalan Bun mempunyai nilai mean 3,76 (Kriteria Sangat Tinggi) yaitu Kontruksi dibangun sepanjang Sungai Arut.
4. Faktor Pelaksanaan pembangunan

Faktor pelaksanaan pembangunan dengan nilai mean 3,40 (Kriteria Tinggi),terdapat 2 faktor di dalamnya yaitu alur transportasi terganggu dan alat kontruksi membuat kebisingan. Faktor yang tanggapan masyarakat terhadap rencana pengembangan Kawasan Waterfront City di Sungai Arut Pangkalan Bun, dan faktor pelaksanaan pembangunan pada alat kontruksi membuat kebisingan yang mempunyai nilai mean yang tinggi 3,42 (Kriteria Tinggi) yang berarti sangat memperngaruhi tanggapan masyarakat terhadap rencana pengembangan Kawasan Waterfront City di Sungai Arut Pangkalan Bun.

5. Faktor Penataan Kawasan Lingkungan Faktor penataan kawasan lingkungan dengan nilai mean 3,28 (Kriteria Tinggi), merupakan faktor yang mempengaruhi tanggapan masyarakat terhadap rencana pengembangan Kawasan Waterfront City di Sungai Arut Pangkalan Bun, dan faktor penataan kawasan pada pembaharuan jembatan mempunyai nilai mean yang paling tinggi 3,76 (Kriteria Sangat Tinggi) yang berarti sangat memperngaruhi tanggapan masyarakat terhadap rencana pengembangan Kawasan Waterfront City di Sungai Arut Pangkalan Bun. Berdasarkan hasil wawancara langsung kepada masyarakat bantaran Sungai Arut, ada beberapa masukan dari masyarakat yaitu jembatan atau gertak yang ada tidak di rombak namun dijadikan sebagai sarana pejalan kaki, sedangkan kontruksi jalan dengan pile slab sebaiknya dibangun berdampingan dengan jembatan atau gertak yang sudah ada, sehingga kendaraan roda dua maupun roda empat tidak mengganggu pejalan kaki. Selain itu 
jembatan atau gertak yang ada, terbuat dari kayu bulin yang sudah ada sejak dulu sehingga dapat dijadikan peninggalan sejarah yang dapat menjadi daya tarik tersendiri bagi wisatawan asing maupun lokal.

\section{KESIMPULAN}

Berdasarkan hasil penelitian dan pembahasan dapat disimpulkan sebagai berikut: Urutan faktor - faktor yang mempengaruhi tanggapan masyarakat terhadap rencana pengembangan Kawasan Waterfront City di Sungai Arut Pangkalan Bun adalah :

1. Faktor Pengembangan Kawasan, dengan mean 3,82

2. Faktor Operasional dan Pemeliharaan, dengan mean 3,63

3. Faktor Sosialisasi Masyarakat, dengan mean 3,59

4. Faktor Pelaksanaan Pembangunan, dengn mean 3,40

5. Faktor Penataan Kawasan Lingkungan, dengan mean 3,28

Dari hasil urutan faktor diatas maka dapat di tarik kesimpulan faktor yang paling mempengaruhi tingkat tanggapan masyarakat yaitu faktor Pengembangan kawasan dengan nilai mean 3,82. Maka masyarakat pinggiran Sungai Arut ingin kawasan permukiman mereka dikembangkan seiring dengan perkembangan zaman.

\section{SARAN}

Berdasarkan hasil penelitian, analisis penelitian serta kesimpulan dapat disarankan sebagai berikut :

1. Bagi pemerintah agar dalam waktu cepat melaksanakan kontruksi pembangunan Waterfront City dikawasan tepi Sungai Arut Pangkalan Bun karena antusiasme masyarakat pinggiran Sungai Arut yang begitu besar dalam menanggapi rencana pembangunan Waterfront City, dapat dilihat dari hasil kuesioner yang mereka berikan.

2. Pada Penelitian ini penulis sadar masih banyak kekurangan dalam penelitian ini, penulis berharap agar kedepannya dilakukan penelitian lanjutan yang lebih maksimal, penulis menyarankan agar melakukan sosialisasi lebih lanjut kepada masyarakat pinggiran sungai arut mengenai konsep kontruksi Waterfront City yang akan dibangun, agar didapat data yang lebih konkrit dan terpercaya.

3. Pada penelitian ini kami hanya ingin mengetahui tanggapan masyarakat terhadap rencana pengembangan Kawasan Waterfront city di Sungai Arut Pangkalan Bun. penulis berharap kedepannya dilakukan penelitian lanjutan mengenai kontruksi Waterfront City. Saran dari penulis untuk melakukan penelitian diantaranya tingkat kepuasan warga pinggiran sungai arut dengan hasil kontruksi Waterfront City yang telah dibangun.

\section{DAFTAR PUSTAKA}

Delima, Siti, 2015, Peran Pemangku Kepentingan Dalam Realisasi Konsep Waterfront City di Kota Palembang, Skripsi . Yogyakarta : Universitas Gadjah Mada.

Hendri, Jhon, 2009, Merancang Kuisioner, Depok : Universitas Gunadarma.

Online Digiulib, 2013, Metode Deskriptif. Diakses pada tanggal 16 Oktober 2018, dari http://digilib.unila.ac.id/881/11/3. $\% 20 \mathrm{BAB} \% 20 \mathrm{III}$

Online Digilib, 2015, Tinjauan Tentang Respon Masyarakat. Diakses pada tanggal 11 Juli 2018, dari http://digilib.unila.ac.id/16336/14/

Online Respository, 2017, Respon Masyarakat pada program Dana Desa di Desa Kutambaru Kecamatan Munte Kabupaten Karo. Diakses pada tanggal 11 Juli 2018, dari http://repository.usu.ac.id/bitstream/han dle/123456789/31904/

Online sindonews, 2018, Waterfront city di sungai arut. Diakses pada tanggal 12 Oktober 2018, dari https://daerah.sindonews.com

Online Pemkab, 2018, Gambaran Umum Kabupaten Kotawaringin Barat.Diakses pada tanggal 12 Oktober 2018, dari http://pemkab.kotawaringinbaratkab.go. 
id/page/2/Gambaran-Umum-

Kabupaten-Kotawaringin-Barat

Online Wikipedia, 2014, Sosialisasi. Diakses pada tanggal 14 Juli 2018, dari https://id.wikipedia.org/wiki/Sosialisasi

Perdana Echo, 2016, Olah data Skripsi Dengan SPSS 22. LAB KOM Manajemen FE UBB, Pangkalpinang.

Pujihastuti, Isti, 2010, Prinsip Penulisan Kuisioner Penelitian. Jurnal FAPERTA : CEFARS

Singarimbun, Masri dan Effendi, Sofian, 1989, Metode Penelitian Survai. Jakarta :LP3ES. 